\title{
CORRECTION
}

\section{Correction to: The Effects of Droplets and Bubbles on On-orbit Propellant Volumetric Measurements Using Cavity Resonances}

\author{
Xin $\mathrm{Li}^{1} \cdot$ Zhen $\mathrm{Li}^{2} \cdot$ Ruofan Zhang ${ }^{2} \cdot$ Xiang Zhang $^{3} \cdot$ Yong Chen ${ }^{1,4}$
}

Published online: 10 February 2022

(c) Springer Nature B.V. 2022

Correction to: Microgravity Science and Technology https://doi.org/10.1007/s12217-021-09924-1

The original version of this article unfortunately contained an incorrect order of affiliation(s) for Author Xin Li from National University of Defense Technology, Changsha,

China to Beijing Institute of Technology, Beijing, China. This was sent after this article was publshed.

The corrected affiliation is shown below.

Publisher's Note Springer Nature remains neutral with regard to jurisdictional claims in published maps and institutional affiliations.

The original article can be found online at https://doi.org/10.1007/ s12217-021-09924-1.

Yong Chen

literature_chen@nudt.edu.cn

Xin Li

253474946@qq.com

Zhen $\mathrm{Li}$

literature_lizhen@foxmail.com

Ruofan Zhang

zrf_nudt@163.com

Xiang Zhang

zxstudy@hotmail.com

1 National University of Defense Technology, Changsha, China

2 College of Aerospace Science and Engineering, National University of Defense Technology, Changsha, China

3 National Innovation Institute of Defense Technology, Academy of Military Science, Beijing 100071, China

4 Chengdu Fluid Dynamics Innovation Center, Chengdu, China 